\title{
MtDNA ND2 sequence identifies Streaked Horned Lark (Eremophila alpestris strigata) from birdstrike to US Air Force F-15 at Portland International Airport, Oregon
}

\author{
Carla J. Dove • Nor Faridah Dahlan • \\ Sergei V. Drovetski
}

Received: 23 April 2013/Accepted: 6 May 2013/Published online: 14 May 2013

(C) The Author(s) 2013. This article is published with open access at Springerlink.com

\begin{abstract}
The Streaked Horned Lark (SHL: Eremophila alpestris strigata) is the Northwest subspecies of the Horned Lark listed as endangered in Washington State, critical in Oregon, and is now being considered for listing as threatened by the US Fish \& Wildlife Service. Some of the important breeding areas of SHL are associated with airports in western Washington and Oregon which raises concern over possible collisions between SHLs and aircraft. Here, we report a successful use of mtDNA ND2 gene sequence for identification of SHL feather and tissue remains from a bird collision with a US Air Force F-15-C on 4 October 2012 at Portland International Airport. Due to the conservation status of SHL, documentation of this event and a simple mtDNA-based molecular identification protocol may have management and conservation implications at airfields within the range of this rare subspecies.
\end{abstract}

Keywords Portland International Airport - Birdstrike . F-15 - DNA $\cdot$ Streaked Horned Lark

\section{Introduction}

The Horned Lark (Eremophila alpestris) is a common wide-ranging passerine of Holarctic arid lands, alpine and Arctic tundras that breeds throughout a large portion of

\section{J. Dove $(\bowtie) \cdot$ N. F. Dahlan}

Feather Identification Lab, Division of Birds, Smithsonian Institution, NHB E-600, MRC 116, Washington, DC 20560, USA

e-mail: dovec@si.edu

S. V. Drovetski

Tromsø University Museum, 9037 Tromsö, Norway
North America (Beason 1995). Fifteen of the 21 currently recognized subspecies within the North American range (American Ornithologist Union Checklist 1957) occur in the western US and Canada. The Streaked Horned Lark (SHL: Eremophila alpestris strigata) is a rare subspecies of Horned Lark that is confined to a breeding range along the coast from southern British Colombia to Oregon (Beason 1995) and is now being considered for listing as threatened by the US Fish \& Wildlife Service (Federal Register Vol. 77, No. 197 October 11, 2012). Regardless of the federal decision, this subspecies is already state listed as critical in Oregon (Oregon Department of Fish and Wildlife Sensitive Species, p. 12, 2008) and endangered in Washington (Washington Department of Fish and Wildlife, 2011 Annual Report, p. 58). In light of this, extensive study in recent years has summarized and quantified habitat loss, documented current breeding and wintering ranges, and analyzed the genetic differences among SHL and other Horned Lark subspecies inhabiting the Pacific Northwest (Drovetski et al. 2005 and references therein). The general habitat of SHL is similar to that of other subspecies and includes barren country, areas with short vegetation, and brushy flats (Beason 1995). The close association of SHL with airports has caused heightened awareness and concern among airport biologists and conservation managers in regard to potential bird-aircraft collisions (hereafter "birdstrikes") in the region where this subspecies occurs.

Here, we report the protocols and details of the identification of a Streaked Horned Lark birdstrike that occurred to a US Air Force (USAF) F-15C aircraft at Portland International Airport (PDX). The USAF Oregon Air National Guard's 142 Fighter Wing at PDX reported the birdstrike on 04 October 2012 at $1200 \mathrm{~h}$. Damage to the F-15C was noted to the \#1 engine, first stage blade. The final cost of repair was recorded as US $\$ 800$. 


\section{Methods}

The bird remains (several small feathers and tissue particles) were retrieved directly from the \#1 engine. The retrieved feathers lacked sufficient diagnostic characters for positive morphological identification to the subspecies level, so we first attempted to use "DNA barcoding" which involved comparison of the mtDNA cytochrome $c$ oxidase 1 (CO1) nucleotide sequence from the birdstrike sample to a database of vouchered CO1 sequences with known taxonomy (Hebert et al. 2003; Dove et al. 2008).

Total genomic DNA was extracted from frozen tissue of a vouchered museum specimen from Oregon (USNM 602465; Genbank Acces. Number: KC954609) and the tissue particles included with the birdstrike sample using Qiagen DNeasy Blood and Tissue Kit. The CO1 fragment for the birdstrike sample was amplified according to the standard barcoding protocol (Kerr et al. 2009) and sequenced in the forward direction only. The sequence was then compared to the on-line Barcode of Life Database (BOLD) http://www. boldsystems.org/ (Ratnasingham and Hebert 2007).

Because the location of this strike was within the current range of the SHL, and previous genetic work reported a single distinct mtDNA [NADH-ubiquinine oxidoreductase chain 2 (ND2)] haplotype for 31 SHLs (Drovetski et al. 2005), we further conducted the molecular identification using the ND2 gene to determine whether the birdstrike sample belonged to the strigata haplotype. We also sequenced ND2 for the vouchered sample of SHL (USNM 602465) from the Portland International Airport.

Our laboratory procedures and PCR profile for ND2 amplification followed Drovetski et al. (2004). For both samples the mtDNA ND2 gene was amplified using GoTaq ${ }^{\circledR}$ (Promega, Wisconsin, USA) PCR reagents with primers L52 15-TATCGGGCCCATACCCCGAAAAT (Hackett 1996) and H1064 CTTTGAAGGCCTTCGGTTTA (Drovetski et al. 2004). The fragments were sequenced on ABI 3730 using amplification primers and an internal primer L347 CCATTC CACTTCTGATTCCC (Drovetski et al. 2004).

\section{Results and discussion}

The forward CO1 sequence of the birdstrike sample yielded 672 bp: ATCTTTGGCGCATGAGCCGGATGGTAG GTACAGCCCTAAGCCTTCTCATCCGAGCAGAACTA GGCCAACCCGGCGCCCTGCTAGGAGACGACCAAA TCTACAACGTAATCGTCACAGCCCATGCCTTCGTA ATAATCTTTTTTATAGTTATACCGATTATAATCGG AGGTTTCGGTAACTGACTAGTACCTCTAATAATCG GGGCCCCAGATATAGCATTCCCCCGAATAAATAA CATAAGCTTCTGACTCCTACCCCCATCCTTCСТCСТ CCTTCTAGCCTCCTCCACAGTCGAAACAGGCGCAG
GAACAGGTTGAACCGTGTACCCCCCACTAGCCGG CAACCTAGCCCACGCCGGCGCCTCAGTCGACCTA GCCATCTTCTCCCTCCACCTGGCAGGTATCTCATC AATCCTAGGGGCCATCAACTTCATCACCACAGCC ATTAACATAAAACCCCCAGCCCTATCCCAATATCA AACCCCTCTATTCGTTTGATCGGTCCTAATCACCG CCGTACTTCTACTTCTTTCCCTCCCCGTACTAGCTG CCGGCATCACCATGCTACTTACCGACCGCAACCTC AATACTACCTTCTTCGACCCCGCAGGCGGAGGAG ACCCAATCCTCTACCAGCATCTATTCTGATTCTTT GGCCACCCAGAAAATAAAA and matched $99.37 \%$ to the library sequence of Horned Lark (Eremophila alpestris) and confirmed the identification to the species level.

The complete ND2 sequence (1,041 bp) of the birdstrike sample is: ATGAACCCCCAAGCAAAACTGATCTTTA TTTCCAGCCTCCTCCTAGGAACCACCATCGTAATC TCAAGCAACCACTGAATCACCGCCTGAGCCGGAC TCGAAATCAATACTCTAGCCATCCTCCCTCTGATC TCAAAATCCCACCACCCCCGAGCTATCGAAGCCG CCACCAAATACTTCCTTACACAGGCAACCGCCTCC GCCCTTCTACTGTTCTCCAGCATAACAAATGCCTG ACACACAGGACAATGAGATATTACCCAAATAACC CACCCAACATCATGTCTCATCCTAACCTCAGCTCT TGCAATAAAACTAGGACTAGTCCCATTCCACTTCT GATTCCCCGAAGTTCTCCAAGGCTCCCCCCTCATC ACTGGCCTACTACTCTCCACAGCCATAAAACTACC ACCAATCACACTACTCTATATAACCGCCCAATCCC TAAACCCAACAGTGCTAACCGGCATAGCCATTCT ATCCGCAGCTCTGGGGGGCTGAATAGGGCTAAAC CAAACACAAGTCCGAAAAATCCTGGCCTTCTCATC TATCTCCCACCTTGGATGAATAGCTATTATCCTAG TCTACAACCCTAAACTCACCCTGTTAAACTTCTAC CTATACACCCTAATAACTGCAGCCATCTTCCTCAC CCTAAACTCAACCAACACCACAAAACTATCTACC CTAATAACTTCGTGAACCAAAGCCCCTGCACTAA GTGCAATGCTTATACTAACCCTACTATCCCTAGCA GGCCTACCACCCCTAACAGGATTCCTCCCCAAATG ACTTATCATTCAAGAACTAACTAAACAGGAGATA ACTCCCGCAGCAACTATCATTGCACTTCTCTCCCT CCTAGGATTATTTTTCTACCTCCGCCTCGCATACT GTGCAACAATTACACTACCCCCACACTCCACAAAT CACATAAAACAGTGGCATACCAACAAACCCATTC CCTCCTCTATTGCCATCCTAACCGTCCTATCCACG ACACTCCTCCCTCTATCCCCCATAATCTCСCССАC CATCTAA.

The birdstrike ND2 sequence was identical to that found in all 31 SHL samples used by Drovetski et al. (2005, Genbank accession numbers: DQ187437-DQ187467). This haplotype is distinct from all other western Horned Larks and differs by 3 substitutions from the two most closely related haplotypes found in California (Fig. 2 in Drovetski et al. 2005). The vouchered sample (USNM 602465) from 
the Portland International Airport also carried the same SHL ND2 haplotype and provided additional support for the identification of the birdstrike as belonging to this rare subspecies.

Horned Larks are one of the most common species involved in nationwide birdstrikes to USAF and civil aircraft in the USA. In a 21-year review of civil birdstrkes, Dolbeer et al. (2012) reported a total of 1,400 Horned Lark birdstirkes for a total economic loss of US\$ 576,121 (p. 50). The USAF recorded 2,474 Horned Lark birdstrikes during 1995-2012 with damage reported at US\$2,064,370 and ranked this species number 27 out of the top 50 by cost http://www.afsec.af.mil/shared/media/document/AFD-080 130-040.pdf.

The US Fish \& Wildlife Service is proposing to designate 12,159 acres of critical habitat in Washington and Oregon as protected. In Washington, the proposed critical habitat airfield units include three training areas and two military airfields (at Joint Base Lewis-McChord in Pierce County) and two civilian airports (Olympia Airport in Thurston County and Sanderson Field in Mason County). In Oregon, the proposed critical habitat units includes 5 civilian airports: Portland International Airport, and regional airports in McMinnville, Salem, Eugene and Corvallis (http://www.fws.gov/wafwo/TCB_SHLcrithab.html). Special rule 4(d) is also proposed to exempt the "take" or harm of this species if it is associated with civilian airport maintenance and operation, and agriculture management.

The prior genetic work conducted on this subspecies (Drovetski et al. 2005) allowed us to confidently identify the remains from the Streaked Horned Lark birdstrike in this case. More research is needed across a broader range for the Horned Larks to help determine the specific areas of mortality from aircraft, and to help define where the most significant problems occur.

Acknowledgments We thank Nick Atwell for the donation of a salvaged SHL specimen (USNM 602465) from PDX for this study and J. F. Whatton for specimen preparation. Randy Moore (Oregon State University) confirmed the status of SHL at PDX. Kevin Kerr provided comments on the manuscript. The Feather Lab is funded through interagency support from USAF, US Navy and the Federal Aviation Administration. Dan Sullivan and Tiffany Robertson provided information regarding this USAF birdstrike. We thank MSgt John Peterson (USAF) and Nick Atwell (PDX) for reporting this birdstrike.

Open Access This article is distributed under the terms of the Creative Commons Attribution License which permits any use, distribution, and reproduction in any medium, provided the original author(s) and the source are credited.

\section{References}

American Ornithologists' Union (1957) Check-list of North American birds, 5th edn. American Ornithologists' Union, Washington, DC

Beason RC (1995) Horned Lark (Eremophila alpestris). In: Poole A (ed) The birds of North America. Cornell Lab of Ornithology, Ithaca. Online. http://bna.birds.cornell.edu/bna/species/195. doi: 10.2173/bna. 195

Dolbeer RA, Wright SE, Weller J, Begier MJ (2012). Wildlife strikes to civil aircraft in the United States 1990-2011. Federal Aviation Administration National Wildlife Strike Database serial report number 17. Report of the Associate Administrator of Airports Office of Airport Safety and Standards Airport Safety \& Certification, Washington DC, Feb 2012. http://www.faa.gov/ airports/airport_safety/wildlife/resources/media/bash90-11.pdf. Accessed 17 April 2013

Dove CJ, Rotzel NC, Heacker M, Weigt L (2008) Using DNA barcodes to identify bird species involved in birdstrikes. J Wildl Manag 72(5):1231-1236. doi:10.2193/2007-272

Drovetski SV, Zink RM, Fadeev IV, Nesterov EV, Koblik EA, Red'kin YA, Rohwer S (2004) Mitchondrial phylogeny of Locustella and related Genera. J Avian Biol 35:105-110

Drovetski SV, Pearson SF, Rohwer S (2005) Streaked horned lark Eremophila alpestris strigata has distinct mitochondrial DNA. Conserv Genet 6:875-883. doi:10.1007/s10592-00509074-9

Hackett SJ (1996) Molecular phylogenetics and biogeography of tanagers in the genus Ramphocelus (Aves). Mol Phylogenet Evol 5:368-382

Hebert PDN, Cywinska A, Ball SL, deWaard JR (2003) Biological identifications through DNA barcodes. Proc R Soc B Biol Sci 270. doi: 10.1098/rspb.2002.2218

Kerr KCR, Lijtmaer DA, Barreira AS, Hebert PDN, Tubaro PL (2009) Probing evolutionary patterns in Neotropical birds through DNA barcodes. PLoS ONE 4(2):e4379. doi:10.1371/ journal.pone.0004379

Ratnasingham S, Hebert PDN (2007) BOLD: The bardcode of life datasystem (http://www.barcodinglife.org) Mol Ecol Resour 7(3):355-364. doi:10.1111/j.1471-8786.2007.01678x 